\title{
Concentrated Learning Experiences Across Two Different Health-Systems
}

\section{Sarah A. Nisly, PharmD, BCPS, FCCP'; Brennen T. Guzik, BS, PharmD Candidate'; Alexandra L. Cunha, PharmD Candidate;} Brittany A. Sturdivant, PharmD Candidate ${ }^{3}$; Lisa F. Brennan, PharmD, BCPS ${ }^{1}$; Jamielynn Sebaaly, PharmD, BCPS ; Susan Smith, BS, PharmD, BCPS ${ }^{1}$

${ }^{1}$ Wingate University; ${ }^{2}$ Campbell University; ${ }^{3}$ High Point University; ${ }^{4}$ ProCE, LLC

*At the time of this work, Dr. Sebaaly was at Wingate University.

\begin{abstract}
Background: While many public pharmacy schools have an adjoining health-system to accommodate their students, some pharmacy programs form partnerships with non-affiliated health-systems to precept students. These health-systems often afford students the opportunity to complete multiple rotations within a single organization, offering decreased onboarding time and more longitudinal experiences.

Innovation: Two autonomous partnerships were developed with independent healthcare systems for concentrated learning experiences during the advanced pharmacy practice experiences year. Each program differs in student requirements and is overseen by the practice site, with participation by area faculty.

Key Findings: A survey assessed professional skill set development, achievement of program goals during the experiential year, and student satisfaction of a concentrated learning experience. A comparison between programs was completed to assess for consistency in student experiences. Nineteen students (83\%) responded to the survey. Students from both health-systems reported similarities in professional skill growth. Likewise, all students reported achievement of program goals and overall satisfaction with their experiential training.

Conclusions: Independently managed concentrated learning experiences provided evidence of consistent growth in student professional development and achievement of programmatic goals. Partnerships with non-affiliated healthcare systems can provide a rich training ground for student learners.
\end{abstract}

Keywords: APPE, perceptions, student, longitudinal experiences

\section{DESCRIPTION OF THE PROBLEM}

Education in healthcare is contingent on healthcare sites and clinical practitioners to provide experiential training to their learners. To ensure diversity of education, the Accreditation Council for Pharmacy Education (ACPE) requires students to complete Advanced Pharmacy Practice Experiences (APPE)s in community, ambulatory care, hospital, and inpatient general medicine settings. ${ }^{1}$ Some schools and colleges of pharmacy have access to a university-associated health-system enterprise that can serve as a primary experiential education site, encompassing many of the required APPEs. This approach allows for continuity of training and streamlining the rotation scheduling process. ${ }^{2} \mathrm{~A}$ similar approach can provide benefit for unaffiliated pharmacy schools. Partnerships formed between unaffiliated health-systems and schools may provide a rich learning opportunity, and potentially create a network of diverse schools and learners. Likewise, unaffiliated schools may have flexibility to form partnerships with a wide breadth of

Corresponding author: Sarah A. Nisly, PharmD, BCPS, FCCP

Wingate University, $515 \mathrm{~N}$. Main St

Wingate, NC 28174

Phone: 336-713-1938; Email: s.nisly@wingate.edu institutions, and allow learners to select a program that best meets their needs. Importantly, unaffiliated institutions may not be familiar with the school curriculum, and should be routinely assessed to ensure experiential learning complements the didactic curriculum and facilitates the transition of student to practitioner. ${ }^{2}$

Concentrated learning experiences, or block scheduling, enable students to strengthen clinical and professional skills in an individual healthcare setting while decreasing orientation and onboarding time. ${ }^{3,4}$ Recent research has highlighted students applying to these programs might be more career-driven or higher performers. ${ }^{5}$ The application process may mirror is the process seen in post-graduate education: a letter of intent, supporting transcript, and interviews by a panel of faculty and pharmacists. Interestingly, this may contribute to the finding that students completing a concentrated experience are more likely to match to a residency program. ${ }^{2}$ Despite the lack of standardization for concentrated learning experiences, the use of either an affiliated or unaffiliated partnership may promote student learning during experiential education.

\section{THE INNOVATION}

Currently, there is a paucity of literature comparing perceptions of APPE partnerships at multiple healthcare system sites. To date, literature is limited to a single partnership between one 
pharmacy program and one healthcare site. ${ }^{2-5}$ Wingate University School of Pharmacy (WUSOP) consists of the main campus in Wingate, NC, and a satellite campus in Hendersonville, NC. For APPE rotations, pharmacy students are assigned to one of five regions within the state. The school has partnerships within two of these regions, Atrium Health's Carolinas Medical Center (CMC) in Charlotte, NC, and Wake Forest Baptist Health (WFBH) in Winston-Salem, NC. Each experience differs slightly in structure and requirements, with administrative oversight by the healthcare system (Table 1). However, both programs promote the following benefits: availability of elective rotations, education with pharmacy residents, longitudinal research project and teaching opportunities, exposure to hospital pharmacy practice, career development, and preparation for post-graduate practice. Wingate students selected for these programs complete a minimum of six rotations, each a 5-week block, up to a maximum of eight. The order of rotation experiences varies by student and is based on preceptor availability. One required rotation for long-term care is completed outside of the concentrated learning experience.

Table 1: Concentrated Experience Comparison

\begin{tabular}{|c|c|c|}
\hline Characteristics & Carolinas Medical Center & Wake Forest Baptist Health \\
\hline System type & 850 bed Academic Medical Center & 800 bed Academic Medical Center \\
\hline Total pharmacy learners & $\begin{array}{l}\text { APPE students ( } 2 \text { schools) } \\
\text { IPPE students ( } 1 \text { school) } \\
\text { Six PGY1 residents } \\
\text { Two PGY2 residents }\end{array}$ & $\begin{array}{l}\text { APPE students ( } 3 \text { schools) } \\
\text { IPPE students ( } 2 \text { schools) } \\
\text { Eight PGY1 residents } \\
\text { Eight PGY2 residents }\end{array}$ \\
\hline $\begin{array}{l}\text { Schools eligible for the } \\
\text { concentrated learning } \\
\text { experience }\end{array}$ & University of North Carolina, Wingate University & Wingate University \\
\hline $\begin{array}{l}\text { Number of students } \\
\text { accepted }\end{array}$ & Maximum of 10 & Maximum of 18 \\
\hline Application process & $\begin{array}{l}\text { Student CV, application form, and two letters of } \\
\text { recommendation }\end{array}$ & $\begin{array}{l}\text { Student CV, application form, and two letters } \\
\text { of recommendation }\end{array}$ \\
\hline Selection process & $\begin{array}{l}\text { Application packet reviewed by Student } \\
\text { Program Steering Committee with input from } \\
\text { APPE Director }\end{array}$ & $\begin{array}{l}\text { Application packet reviewed by faculty } \\
\text { coordinators, hospital coordinator, with input } \\
\text { from APPE Director }\end{array}$ \\
\hline $\begin{array}{l}\text { APPE types and number of } \\
\text { students/rotation }\end{array}$ & $\begin{array}{l}\text { One Internal Medicine ( } 1-2 \text { students/rotation), } \\
\text { one Advanced Hospital ( } 1 \text { student/rotation), } \\
\text { one community ( } 1 \text { student/rotation), and three } \\
\text { Electives ( } 1 \text { student/rotation) }\end{array}$ & $\begin{array}{l}\text { One Internal Medicine ( } 2 \text { students/rotation), } \\
\text { one Advanced Hospital ( } 2 \text { students/rotation), } \\
\text { two Community ( } 2 \text { student/rotation), and } \\
\text { three Electives ( } 1 \text { student/rotation) }\end{array}$ \\
\hline Longitudinal Experiences & $\begin{array}{l}\text { One mandatory research project and two } \\
\text { mandatory formal presentations }\end{array}$ & $\begin{array}{l}\text { One optional research project, two } \\
\text { mandatory formal presentations, and four } \\
\text { mandatory nights participation in a student } \\
\text { run free clinic }\end{array}$ \\
\hline Mentorship & Yes, faculty members & $\begin{array}{l}\text { Yes, with faculty members longitudinally and } \\
\text { with pharmacy residents for formal } \\
\text { presentations }\end{array}$ \\
\hline $\begin{array}{l}\text { Residency preparatory } \\
\text { program }\end{array}$ & Yes, run by pharmacy residents & Yes, run by pharmacy residents \\
\hline
\end{tabular}


All third-year student pharmacists are eligible to apply for the concentrated learning experiences, and selection is based on application review by the medical center and practicing faculty at that site. In general, students are evaluated on prior experience, academic performance, and written communication. Each site has its own application process and scoring rubric. Students who applied to the WFBH program could only apply to that site, while students applying to CMC were permitted to apply to more than one site within the larger parent organization, Atrium Health. Additionally, $\mathrm{CMC}^{\prime} \mathrm{s}$ program is open to non-WUSOP students. Both programs function autonomously and have not previously been compared for consistency in student experiences. As such, we conducted a quality assurance study to assess for differences in student perceived skill set development, and professional growth between the two concentrated learning experiences.

\section{CRITICAL ANALYSIS}

All students from the 2017 WUSOP graduating class, who participated in a concentrated learning experience at an affiliated academic medical center, were eligible for inclusion. This was a single-institution, investigational review boardapproved, survey-based research study. The survey instrument was developed by the authors using QualtricsXM (Qualtrics Labs Inc., Provo, UT) and was distributed electronically via university email addresses to students during their final experiential trimester. Participation in the survey was voluntary and all survey results were anonymous.

Student-perceived changes in clinical and professional development skills from start to completion of APPEs centered on seven areas: critical thinking skills, drug information evaluation, medical team engagement, presentation skills, time management, verbal communication, and written communication. Students were asked to reflect on their skill level at the start of their APPE year compared to the end of their APPE year. Using whole numbers from 1 to 10 (1=weak, $10=$ strong), students assigned a number to each skill at both points in time. Skill set development between the two concentrated learning experiences were analyzed for differences. To determine overall student satisfaction with program goal achievement, students were asked to rate their experience using a five-point Likert scale ( $1=$ not well at all, $5=e x t r e m e l y$ well). Students were asked to rate their progress in achievement of program goals in the areas of teaching, research, career development, opportunities with residents, preparation for residency training, and exposure to hospital pharmacy. Information was collected to analyze aggregate student responses.

Descriptive and inferential statistics were used. Changes in student perceptions were analyzed with a Mann-Whitney U. Differences between programs were assessed using a repeated measures ANOVA. All statistical tests were performed using IBM SPSS Statistics for Windows (Version 25.0, International Business Machines Corp, Armonk, NY).
A total of 23 students were eligible for participation: six students from $\mathrm{CMC}$ and 17 students from WFBH. Survey responses were received from $83 \%(n=19)$ : six $(31.5 \%)$ from CMC and thirteen (68.4\%) from WFBH. Median skill development for medical team engagement was significantly higher at WFBH than CMC (Figure 1); this was the only significant difference between the two programs $(p<0.05)$.

For goals, all respondents selected "met very well" or "met extremely well" for each individual goal (i.e. teaching opportunities, career development, education opportunities with residents, longitudinal research opportunities, preparation for residency training, and maximizing exposure to hospital pharmacy).

\section{KEY ISSUES}

The individual concentrated learning experiences at WFBH and $\mathrm{CMC}$ were designed to help students strengthen their clinical and professional skills in preparation for post-graduate training and advanced pharmacy practice roles. However, no quality assurance process had been undertaken to date. Pharmacy programs with longitudinal partnerships have a commitment to their students to ensure consistency between offerings. Not surprisingly, we found students at both sites reported significant improvement in all skills self-assessed. Although no formal training was completed to support student selfassessment, we provide a "real life" evaluation of perceived student benefit. These findings complement prior research showcasing that pharmacy school and health-system partnerships facilitate participant growth and multidisciplinary engagement. $^{3}$

Despite small differences in program requirements, students were able to meet program goals. Teaching opportunities, educational sessions focused on preparation for residency, and longitudinal research projects all afforded students the opportunity to strengthen their candidacy for post-graduate placement. Previous studies highlighted similar findings, with opportunities in networking, publication, research, and presentations contributing to the satisfaction of students. ${ }^{4}$ Additionally, the longitudinal nature of the programs allowed students to focus on rotations and deliver advanced patient care as opposed to repeated onboarding and becoming acquainted with new facilities.

Our comparison of the two different concentrated APPE program sites showed similarities in students' perception of program benefits and improvement in clinical and professional development skills. A single skill (medical team engagement) resulted in a significant difference in median skill development between programs. These results may be skewed due to WFBH having a larger population size of 13 participants in the study in comparison to six participants at CMC. Importantly, students from this single university received similar perceived program benefits across the board, at two separate health-systems. This is promising news for schools or colleges dependent on 
multiple (affiliated or unaffiliated) institutions for experiential education.

A strength of this study was the assessment of students' perceived clinical and professional skills both pre- and postcompletion of the concentrated learning experiences, which is currently lacking in the literature. The self-assessments benefit the programs by highlighting students' experiences, in order to encourage program evaluation, quality improvement and accumulation of evidence to demonstrate the success of concentrated experiences.

Although prior hospital experience is not required for acceptance into the program, it is possible that students without hospital experience may not as easily adjust to the new environment, and therefore may report a lower baseline experience. Also, there was no assessment of the preceptor's evaluation of the student, and whether that may have influenced perceived skill development by the student.

\section{NEXT STEPS}

Routine quality assurance of programmatic experiences for students is necessary to ensure quality delivery of curricular outcomes. We were able to demonstrate some consistency in independently managed concentrated learning experiences for our APPE students. Future analysis could include correlations of students' GPA, prior pharmacy experience, and grade on rotation to show the potential impact on students' perceived skill development. Additionally, examining student selfawareness through exploration of student performance selfassessment versus preceptor assessment of performance could be hypothesis generating.

Likewise, further expansion of the current program to offer more IPPE and APPE partnerships could be explored. Dennis et al. showed improved APPE performance for students assigned to the same facility during IPPE rotations, as compared to students assigned to separate facilities. ${ }^{6}$ This is potentially due to program benefits, such as decreased onboarding, site familiarity, and longitudinal experiences. Coupled with our APPE findings, exploration of a combined "track" for IPPE and APPEs within institutional partnerships could further develop student learners in partnership with the didactic curriculum. Lastly, formalized self-assessment training may enhance awareness and help evenly compare students participating in the concentrated program and non-program participants to see if there are differences in perceived benefits and student outcomes.
For other institutions, the feasibility of concentrated experiences may hinge on experiential partnerships and preceptor availability. However, investment in a similar structure with multiple programs could minimize experiential interruptions, foster longitudinal experiences, and provide benefit to the site and learner. Starting with a pilot program may allow for individualization and process improvements to garner success in large scale efforts.

Conflicts of Interest: None

Funding/support: None

Acknowledgements: A version of this material has been published in pre-print at:

https://www.authorea.com/users/288003/articles/413047student-perceptions-of-concentrated-learning-experiencesacross-two-different-health-

systems?commit=c8c86e4fdbf430319d4cf74b579cccaf2417af9f

\section{REFERENCES}

1. Accreditation council for pharmacy education. Accreditation standards and key elements for the professional program in pharmacy leading to the doctor of pharmacy degree. Standards 2016. https://www.acpeaccredit.org/pdf/Standards2016FINAL.pdf. Accessed June 27th, 2020.

2. Hatton RC, Weitzel, KW. Complete-block scheduling for advanced pharmacy practice experiences. Am J Health Syst Pharm. 2013;70(23):2144-2151.

3. Taylor RA, Wisneski SS, Kaun MA, Parteleno P, Williams J, Goldman MP. Sequential advanced pharmacy practice experiences at one institution for students from three pharmacy schools. Am J Health Syst Pharm. 2014;71(2):140-144.

4. Frasiolas JA, Wright K, Dzierba AL. Evaluation of a longitudinal advanced pharmacy practice experience. Am J Pharm Educ. 2017;81(3):Article 1.

5. O'Sullivan TA, Sullivan L, Webber K, Weber SS. Comparison of student outcomes between longitudinally and traditionally placed advanced pharmacy practice experiences. Am J Pharm Educ 2019;83(8):Article 7143.

6. Dennis VC, Britton ML, Wheeler RE, Carter SM. Practice experiences at a single institutional practice site to improve advanced pharmacy practice examination performance. Am J Pharm Educ. 2014;78(3):Article 60. 


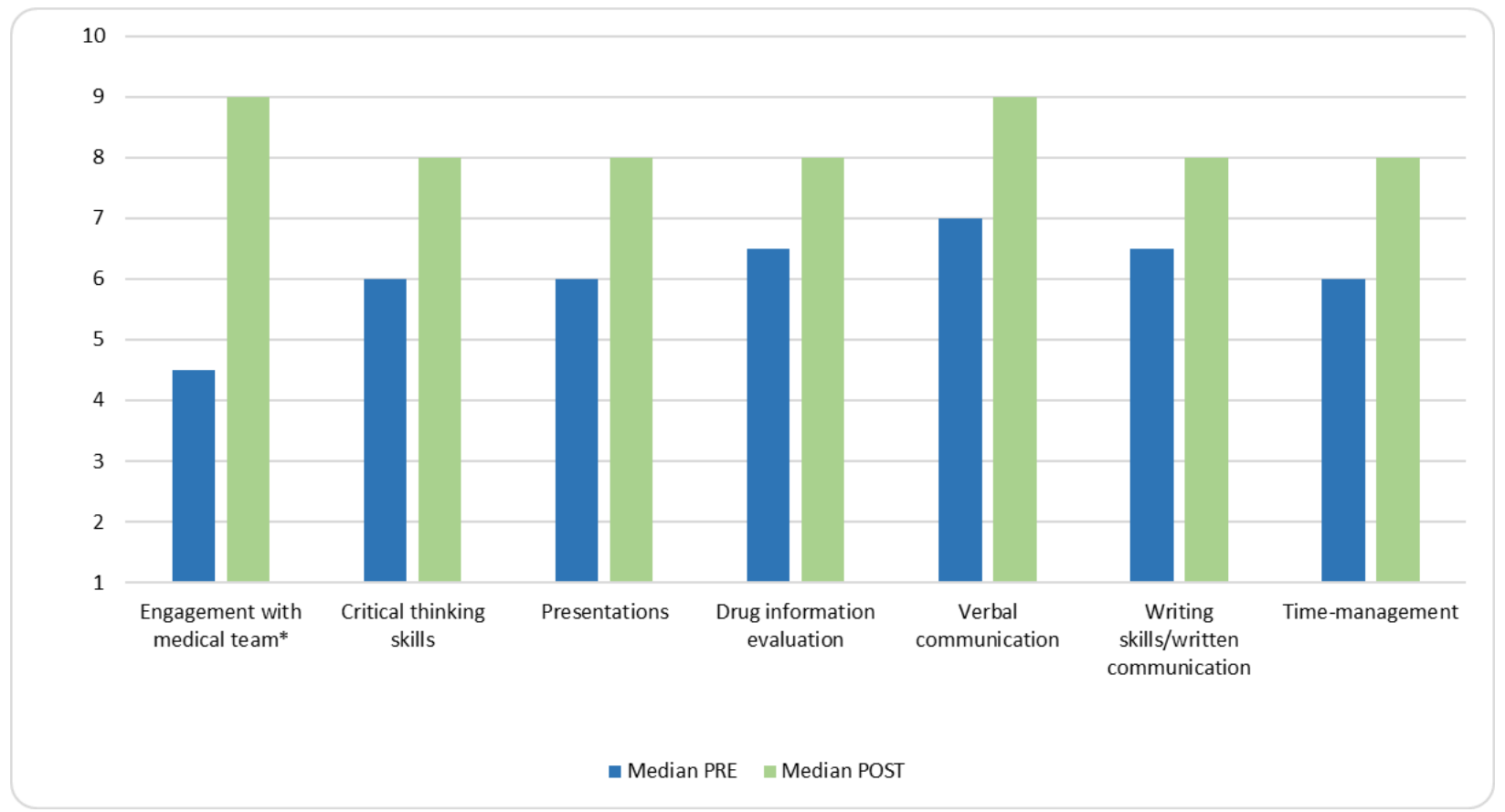

Figure 1. Median student self-assessments pre and post APPE in professional skills Scale 1-10: 1 =weak, $10=$ strong; ${ }^{*} p<0.05$ for difference between programs 